\title{
Use of USSD and Website for Higher Education Lecture Policing in Developing Countries: A Case Study of Federal University of Technology, Minna
}

\author{
Babakano F. J., Oyefolahan I. O., Etuk S. O., Aliyu H. O., Johnson O. I. \\ School of Information and Communication Technology \\ Federal University of Technology, Minna, Nigeria
}

\begin{abstract}
Truancy and/or lateness by lecturers in Nigerian universities have been an aged problem. Though the universities have units that occasionally visit some lecture venues to check whether lectures hold as scheduled or not, the policing officers cannot practically verify that all the lectures scheduled per day in every department of the university had held. This paper presents the Lecture Evaluation and Monitoring System (LEMS), a system that uses Unstructured Supplementary Service Data (USSD) and internet technology to help the university's Quality Assurance and Productivity Unit (QAP) unit to monitor lecture attendances in real time without having to roam the campus. The system also provides statistical summary of the attendance inputs for each lecturer, departments and schools lecture attendance inputs for a given semester.
\end{abstract}

\section{Keywords}

LEMS, Lecturer Policing, Lecture Monitoring System, USSD, Web technology

\section{INTRODUCTION}

Schools particularly in developing countries like Nigeria have the problem of lecture attendance by lecturers which always have negative impacts on the students either in terms of poor performance in the examinations or the amount of knowledge they are able to acquire before they graduate and join the labor force.

Most public universities in Nigeria have units, which as part of their responsibilities, that occasionally visit some lecture venues to check whether lectures hold as scheduled or not and impose appropriate punishment on lecturers that are found wanted in this regard. At the Federal University of Technology Minna (FUTMinna), the Quality Assurance and Productivity Unit (QAP) is saddled with this responsibility.

However, the lectures policing officers cannot practically visit all lecture venues at every time a lecture is meant to hold there in a day considering the size of the university and the numerous lectures scheduled on the timetables of the various faculties and departments.

Human factors can also negatively affect this manual approach to policing; the policing officer himself needs to be monitored to ensure that he actually goes to the lecture venues at the appropriate time and is not falsifying the reports of his observations either in favor of, or against the lecturer in question for many reasons that may come to one's mind. Hence, there is need for a more pragmatic approach to verify that all the lectures scheduled per day in every department of the university had held.*

This paper presents the Lecture Evaluation and Monitoring System (LEMS), a system that combines the Unstructured
Supplementary Service Data (USSD) with internet technology to help the QAP unit monitor lecture attendances in real time without having to roam the campus. The idea is that the QAP unit will only have to appoint a member of a class as an informant that reports the updates on every lecture in real time. We expect that recruiting a student member of a class as the policing officer to report updates on lectures will reduce the chances of compromise for two reasons: 1) the reporter has to always attend the lectures and 2) he understands that the process aims at protecting his interest and that he will be at the receiving end if the lecturer comes late to class or fails to attend classes.

While choosing an internet application to receive updates on LEMS, we are not unmindful of the fact that being a developing country, Nigeria cannot yet boast of reliable internet connectivity for an average citizen. Fortunately, most Nigerians can afford to use the Global System for Mobile communications (GSM), and even the simplest GSM phones support USSD. We take advantage of this accessibility by using the USSD to provide an alternative means by which the student informants can always report lecture updates to LEMS in real time.

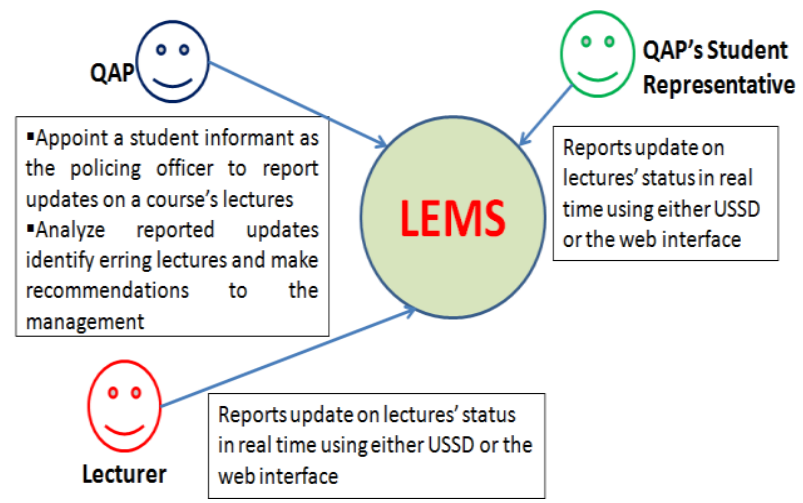

Figure 1. Conceptual framework of LEMS

Figure 1 presents an informal description of the conceptual framework of LEMS; giving an overview of the roles played by its various users in their interactions. By analyzing the reported updates on the various lectures/courses, the QAP can obtain, from LEMS, the statistical summary of the attendance inputs for each lecturer, departments and schools lecture attendance inputs for a given semester.

The rest of this paper is organized as follows: the next section presents a literature review of work done on lecturer's evaluation and attendance monitoring. This is followed by a presentation of the design of LEMS in Section 3 and a demonstration and discussion of its implementation in Section 4. Finally, we conclude the paper with a highlight of its perspectives in Section 5. 


\section{LITERATURE REVIEW}

A number of related work exist on evaluation of lecturers (teachers) using diverse methods and techniques to effectively monitor lecturer's efficiency in carrying out their task of teaching students. It is important to note that there are no generally acceptable methodology for evaluating lecturer's effectiveness and efficiency. In the design and implementing the next Generation of Teacher Evaluation Systems, White et al. [1] assert that Teacher performance measures required by Performance Reform Act (PERA) of the state of Illinois must include both formal and informal classrooms observations, as well as associated professional development.

Curtis [2] designed and implemented Hillsborough County Public Schools Teacher Evaluation System. The system consists of two main components: observations of instruction and teachers' value-added scores, based on student test results.

In another work by Liu and Zhao [3], they presented a webbased University Teachers Evaluation System that supports uniform and comprehensive evaluation criteria with four perspectives from students, teachers-peers, managers and selfevaluation.

In a study in China, Zhao and Meng[4] implemented the Analysis of Indicators in Teachers Evaluation Based on Rough set, they introduced a method which combined discernibility matrix and the distinction function to analyze the data obtained by questionnaire survey, through which they performed optimality test on twenty indicators and obtained the best five optimal indicators that can be used to properly evaluate University Teachers, they asserts that the old method of evaluation using up to twenty indicators for questionnaires brings about ambiguity, waste of time and cannot arrive at a rational and scientific conclusion. Their target was to restructure teacher evaluation indicators for the purpose of guiding the reform of evaluation systems and mechanisms, in order to promote teaching standards and improve teaching quality.

A recent work by Yao-Hua [5] describes the Excellent Teachers Evaluation System in the Blended Learning Environment. The study went further to describe Blended Learning Mode as a new teaching mode, which combines the traditional teaching method and computer assisted instruction, he went further to assert that the lifeline of universities and colleges depends on the quality of teaching. He said that the traditional classroom is mainly based on summary evaluation, and the process evaluation is often neglected because of the difficulty of collecting data, therefore computer assisted lecture can record learning process of learners in real time through the application of information technology and aid in the evaluation of challenges encountered in timely manner. Finally, in a bid to understand the learners' cognitive achievement, learning efforts, progress, motivation and attitude, mixed learning evaluation should not only be based on paper and pencil tests, but also should be in perspective of the whole visual angle of view on the learning process, learning effect and learning attitude.

In another study, the authors of [6] presented a web-based Teachers Evaluation System (TES). The system was divided into four modules namely Basic Information Management, System Management, Evaluation management and Evaluation results feedback. Firstly, The Basic Information Management is to set the data, it includes departments, semester, teachers, students, classes, courses and other data which is the basic for the system. Secondly, the System Management task is to set the index of TES, this involves setting different evaluation parameters for the students, teachers, and experts setting the Evaluation parameter is the core of the TES. Thirdly, The Evaluation Management, manages the work process involves allowing users login to the system users complete operation by prompt. The System Administrator will collect the data and analyze and create Evaluation report and feedback results to the teachers. Finally, the Evaluation Result is to send statistical results to the users. i.e. feedback the evaluation results to teachers and departments, each department analyzes and summarizes teaching quality based on the evaluation results.

The authors of [7] maintain the position that evaluation data can drive better policy and investment decisions at a wide ranging level, including teacher preparation, career pathways, and assessment of professional development. The Measures of Effective Teachers Project found that a combination of teacher effectiveness measures, student achievements gains, student survey results, and observation scores was less prone to error and more likely to predict student learning on a range of student assessments, in comparison to one measure used in isolation. The MET (measures of effective teachers) project showed that very few teachers are low performer also very few are outperforming their peers most teachers fall in the middle when their classroom practices are judged by impartial, trained, and certified evaluators. Also, [8] described a brief study on Teaching Evaluation System Based on Fuzzy Rule with Scientific Teaching Materials, the thesis proposes a more objective and reasonable teaching evaluation method by using fuzzy theory, and provides a new theoretical guidance for the teaching reform of high education and for improvement of teaching quality.

In a study in Nigeria, [9] surveyed the Attitude of Lecturers towards Student's Evaluation of Their Teaching Effectiveness in Nigerian Universities, the result of the analysis of the research question showed that 321 lecturers representing $66 \%$ have positive attitude toward student evaluating their teaching effectiveness while 169 lecturers representing 34\% have a negative attitude. Descriptive survey was used in carrying out the research, the sample comprised of all lecturers in three universities in south-south Nigeria. [10] studied An Evaluation of Teachers' Service Delivery in Nigeria: Measures for Programme Accountability and Improvement, the paper was set out to evaluate teachers service delivery in Lagos state and proffer strategies to make teachers' evaluation a regular exercise for proficiency. A sample of 270 respondents made up of teachers and local education officers was employed. Questionnaires were sent to the respondents to seek their opinions on this issue. The data was analyzed using a combination of qualitative and quantitative method. Respondents are of the opinion that there are a lot of constraints with regards to teachers' service delivery in most of the schools in Lagos State. [11] Proposed Evaluation Technique for Computer Science Studies in Primary and Secondary Schools. in his paper he made it clear that the teaching process is not complete without one form of evaluation or the order, as it help teacher and other stakeholders in determining the effectiveness of their teaching-learning process. The procedure being proposed takes on more the characteristics of students, the course and the programme, but also the effectiveness of the teachers who form a major part of the whole education machinery, $\mathrm{He}$ asserts that for a proper evaluation to be seen to have been conducted, it must be carried out at the following levels: student, teacher and program respectively. In another study on perception, [12] undertook a study on Lecturers' Perception 
towards Students Assessment of their Teaching Effectiveness in a Nigerian University, the study examined lectures perception on student's competency in evaluating lecturers teaching effectiveness, it also examined the lecturer's perception on the formative and summative functions of student's evaluation reports with a view to enhance effectiveness of teaching and learning in the universities. The study adopted a descriptive research design. The Population consist of all academic staff of the Obafemi Awolowo University, Ile-Ife. The sample size was 123 lecturers drawn across seven faculties of the University. Lecturers' responses to the questionnaire were collected and the data were analyzed using appropriate statistical analysis. The results revealed that $82.9 \%$ of lecturers had a very positive perception, $11.4 \%$ had fairly positive while $5.7 \%$ had negative perception.

\section{LEMS' SYSTEM MODEL}

This section provides a brief presentation of the core elements in the design of the LEMS; we cannot present a detailed design due to space limitation. We, however, believe that the level of details provided will be sufficient for the reader to understand the system.

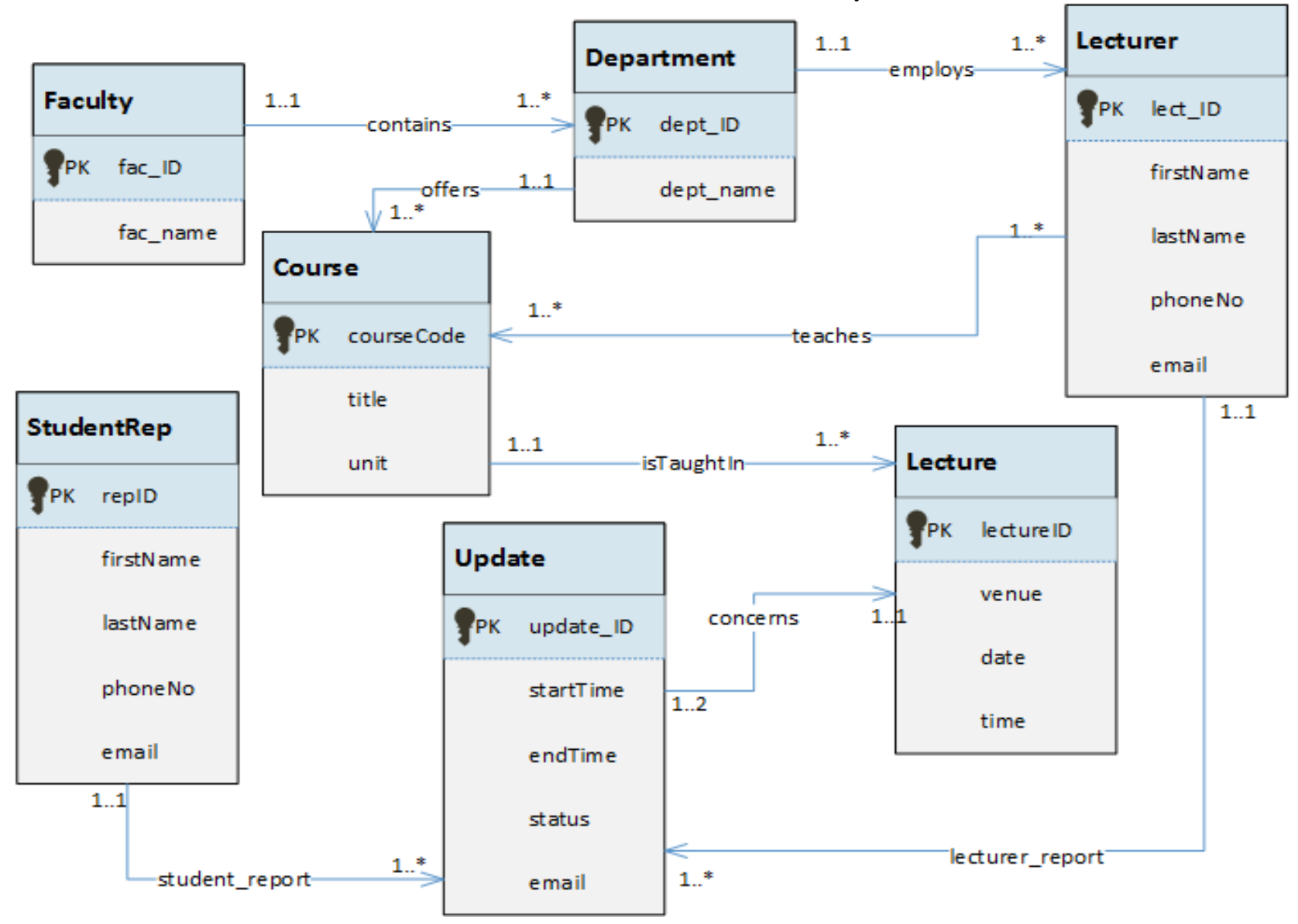

Figure 3. LEMS' data model

\subsection{Functional Requirement}

Figure 2 presents an overview of the major functional requirements of LEMS with respect to the three main users of the system. The "Admin" user in the use case diagram refers to the QAP officer that manages the system. 


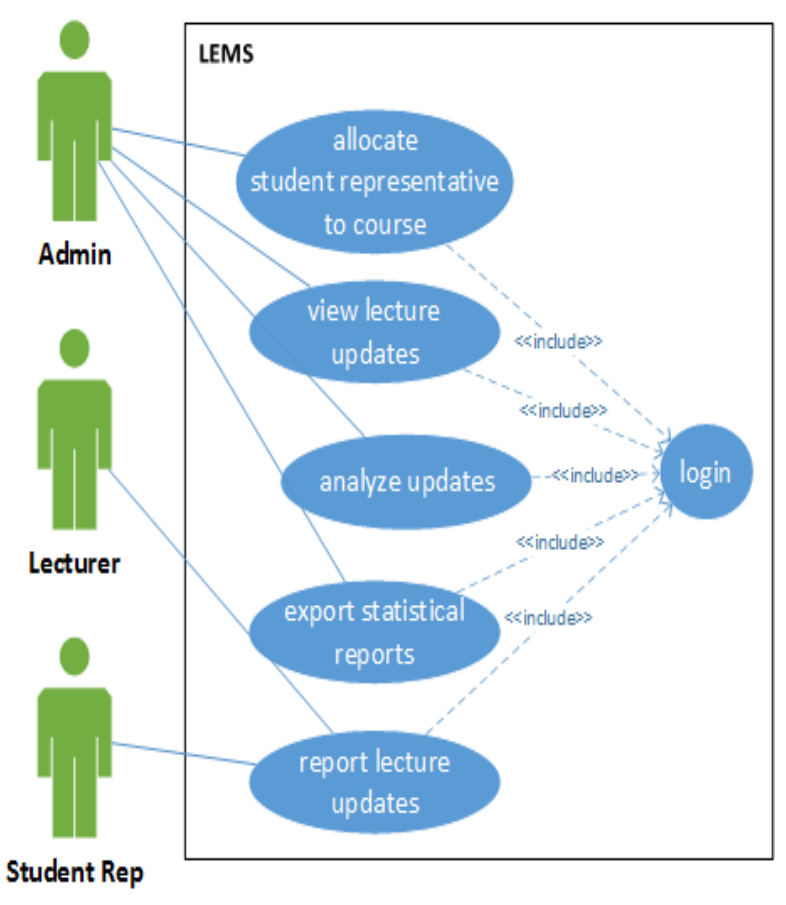

Figure 2. Overview of functional requirements

\subsection{Data Model}

The Entity-Relationship Diagram in Figure 2 presents a model of the data requirement of LEMS. Basically, a faculty/school is a cluster of related departments, each of which offers several courses and employs several lecturers to teach the courses. Every semester, a course is taught in several lectures, at some designated venues and time, by one or more lecturers to whom the course has been officially allocated. At the expected end of every lecture, the lecturer reports an update on the status of the lecture. Likewise, the student informant for the QAP (Student rep), who is unknown to the lecturer, also sends an update to LEMS on the lecture.

\section{DEMONSTRATION OF LEMS}

The system was implemented with PHP and MySQL and integrated with the USSD platform to provide alternative input interface. In subsequent subsections, we present screenshots of some key interfaces in the application.

\subsection{Lecture Updates View}

Figure 4 shows an excerpt from the view of all the lecture updates posted so far in a day. It indicates the details of each lecture, i.e., the course involved and the department and faculty in which it is domiciled, the supposed venue and time of the lecture and the status of the lecture. The status reported can take values from the set \{Held, Absent, Postponed, Other\}. It also shows the start and end times of the lecture; such parameters can be used to quantify the time spent with the students as well as measure the punctualities of the parties involved.

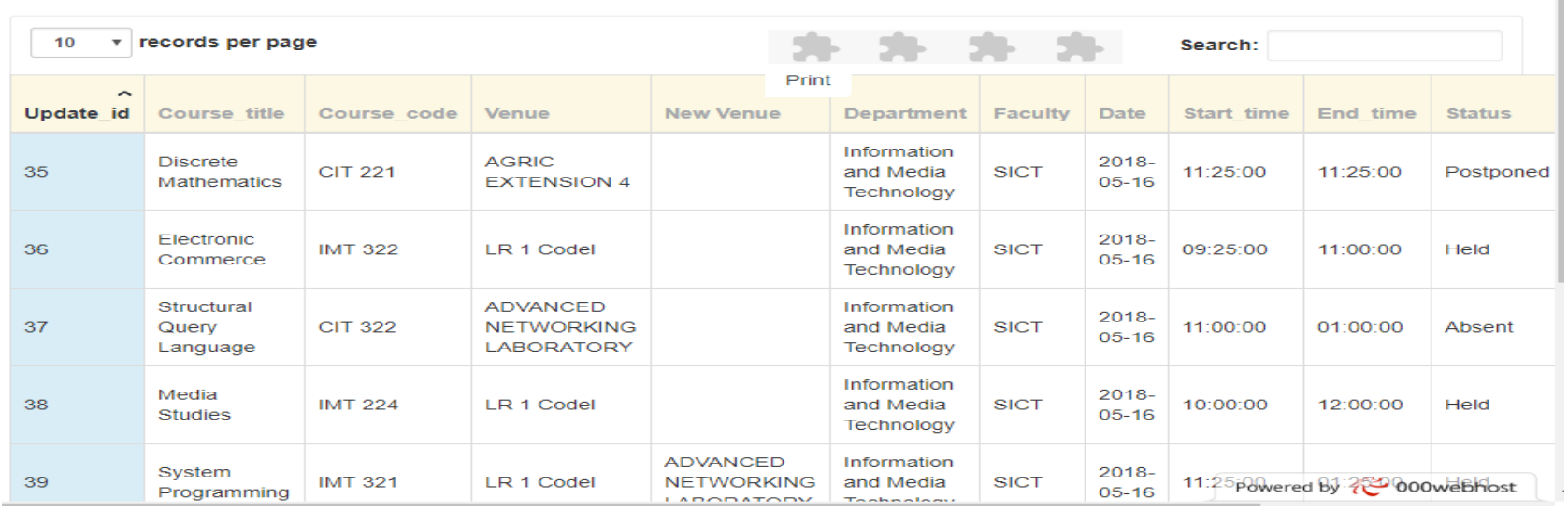

Figure 4. View of daily lecture updates 
Information and Media Technology Daily Lecture Summary

\begin{tabular}{|c|c|c|c|c|c|c|c|c|c|c|c|c|c|c|c|c|c|c|c|c|c|c|c|}
\hline \multicolumn{12}{|c|}{ Lectures Held Today - May 16, 2018, 2:03 pm } & \multicolumn{11}{|c|}{ Lectures Absent Today - May 16, 2018, 2:03 pm } & \multirow[b]{2}{*}{ Period } \\
\hline PF.No & \multicolumn{2}{|l|}{ Name } & \multicolumn{2}{|c|}{ Faculty } & \multicolumn{2}{|c|}{ dept_name } & \multicolumn{2}{|c|}{ Course } & \multicolumn{2}{|c|}{ Level } & status & PE PF.No & Name & \multicolumn{2}{|c|}{ Faculty } & \multicolumn{2}{|c|}{ dept_name } & \multicolumn{2}{|c|}{ Course } & Level & \multicolumn{2}{|c|}{ status } & \\
\hline 87655 & \multicolumn{2}{|c|}{$\begin{array}{l}\text { Dr. } \mathrm{H}, \mathrm{O} \\
\text { Aliyu } \\
\text { Aliyu }\end{array}$} & \multicolumn{2}{|c|}{ SICT } & \multicolumn{2}{|c|}{$\begin{array}{l}\text { Information } \\
\text { and Media } \\
\text { Technology }\end{array}$} & \multicolumn{2}{|c|}{$\begin{array}{l}\text { IMT } \\
321\end{array}$} & \multicolumn{2}{|c|}{300} & Held & $\begin{array}{l}11: 25: 00 \\
-\quad 7677766 \\
01: 25: 00\end{array}$ & $\begin{array}{l}1.0 \\
\text { Alabi }\end{array}$ & \multicolumn{2}{|c|}{ SICT } & \multicolumn{2}{|c|}{$\begin{array}{l}\text { Information } \\
\text { and Media } \\
\text { Technology }\end{array}$} & \multicolumn{2}{|c|}{$\begin{array}{l}\mathrm{CIT} \\
322\end{array}$} & 300 & \multicolumn{2}{|c|}{ Absent } & $\begin{array}{l}\text { 11:00:00 } \\
- \\
01: 00: 00\end{array}$ \\
\hline 8756598 & \multicolumn{2}{|l|}{$\begin{array}{l}\text { Gloria } \\
\text { Eneh } \\
\text { Omale }\end{array}$} & & \multicolumn{2}{|c|}{$\begin{array}{l}\text { Information } \\
\text { and Media } \\
\text { Technology }\end{array}$} & \multicolumn{2}{|l|}{$\begin{array}{l}\text { IMT } \\
224\end{array}$} & \multicolumn{2}{|c|}{200} & Held & $\begin{array}{l}10: 00: 00 \\
- \\
12: 00: 00\end{array}$ & & & & & & & & & & & \\
\hline 234DF & \multicolumn{2}{|c|}{$\begin{array}{l}\text { Faiza } \\
\text { Jada } \\
\text { Babakano }\end{array}$} & \multicolumn{2}{|c|}{ SICT } & $\begin{array}{l}\text { Informati } \\
\text { and Med } \\
\text { Technolo }\end{array}$ & & $\begin{array}{l}\text { IMT } \\
322\end{array}$ & & 300 & & Held & $\begin{array}{l}09: 25: 00 \\
- \\
11: 00: 00\end{array}$ & & & & & & & & & & & \\
\hline Lectu & es Pos & tpo & ned & Tod & lay - Ma & ly 16 & 6,20 & 18 & $2: 0$ & $3 \mathrm{p}$ & & Lectur & ers $A b s$ & sent & for & $\begin{array}{l}\text { Oth } \\
018,\end{array}$ & $\begin{array}{l}\text { er Reas } \\
2: 03 \mathrm{pr}\end{array}$ & $\begin{array}{l}\text { sons } \\
\text { m }\end{array}$ & Toc & day - & May & 16 & \\
\hline PF.No & Name & $\mathrm{Far}$ & culty & dep & t_name & $\mathrm{Cor}$ & urse & Lev & & stat & & Period & & & & & & & & & & & \\
\hline & Mrs. & & & Info & prmation & & & & & & & 1. PF.No & Name & & Fact & ulty & dept_nar & me & Cou & rse & Level & status & 5 Period \\
\hline 6454747 & $\begin{array}{l}\text { Stella } \\
\text { Etuk }\end{array}$ & SIC & & $\begin{array}{l}\text { and } \\
\text { Tec }\end{array}$ & $\begin{array}{l}\text { Media } \\
\text { hnology }\end{array}$ & 221 & & 200 & & Pos & tponed & ${ }^{11}: 35: 4946$ & $\begin{array}{l}\text { Mohamn } \\
\text { Bima }\end{array}$ & ned & $\mathrm{SICT}$ & & $\begin{array}{l}\text { Informati } \\
\text { and Med }\end{array}$ & & $\begin{array}{l}\text { CIT } \\
322\end{array}$ & & 300 & others & $\begin{array}{l}\text { s:03:00:00 } \\
\end{array}$ \\
\hline
\end{tabular}

Figure 5. Departmental summary of lecture update reports

\subsection{Daily Departmental Summary of Lecture Updates}

The screenshot in Figure 5 presents the daily summary of the updates on all lectures of a department as scheduled on the timetable for the day in real time. It stratifies the report based on the status of the lectures. i.e., all lectures of the department that held are reported together; likewise those postponed are reported together and those for which the lecturer was absent are extracted and reported in the same table to give the QAP a quick view of the situation.

\subsection{Daily and Semester-based Summaries on Departments and Faculties.}

The screenshot in Figure 5 presents a statistical summary of the daily lecture updates for every department in a faculty. This gives a macro view of the performances of the various departments in terms of their man-hour inputs. It can help to identify departments whose staffers have a high record of absenteeism.

Similarly, Figure 7 presents a view of the statistical summaries for the various faculties per semester.

Chart (1) Showing SICT Departments and Total Number of lectures held for the Day - May 16, 2018, $1: 59 \mathrm{pm}$
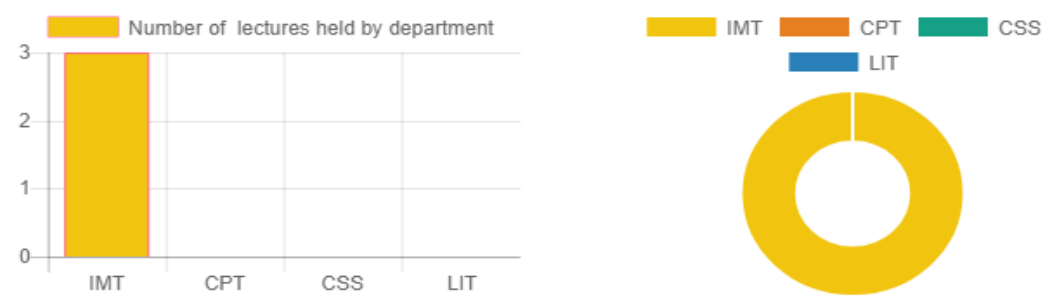

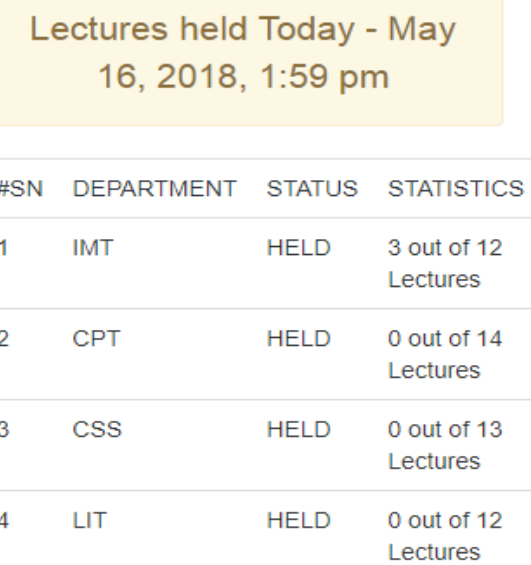

Figure 6. Daily statistical summary of the departmetal lecture reports per faculty 

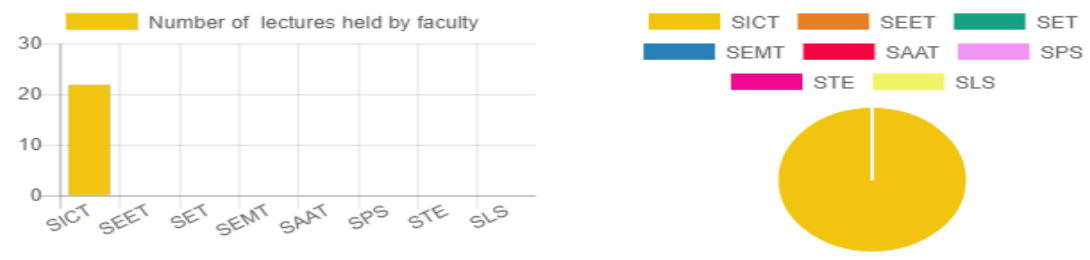

\begin{tabular}{llll}
\hline \multicolumn{3}{c}{ Summary HELD Lectures } \\
\hline \#SN & FACULTY & STATUS & STATISTICS \\
\hline 1 & SICT & HELD & 22 \\
\hline 2 & SEET & HELD & 0 \\
\hline 3 & SEMT & HELD & 0 \\
\hline 4 & SAAT & HELD & 0 \\
\hline 5 & SET & HELD & 0 \\
\hline 6 & SPS & HELD & 0 \\
\hline 7 & SLS & HELD & 0 \\
\hline 8 & SSTE & HELD & 0 \\
\hline
\end{tabular}

Figure 7. Semesterial statistical summaries for the various faculties in the university

\section{CONCLUSION}

In this paper, we have presented the LEMS, a system that employs a combination of internet and USSD technologies for real-time reporting and monitoring lecturers' attitudes to their assigned lectures in a university. With a special attention on developing countries in general and Nigeria in particular in the choice of the choice of technology, we have integrated the USSD to a web application to mitigate the problem of reliable and affordable internet connectivity to ensure that appointed students are able to report updates on lectures in real time to the attention of the university's QAP unit.

The system specifically is meant to tackle the problem of absenteeism of lecturers from lectures or and/or their lateness to classes. With FUTMinna as a case study, it is to replace the traditional method of certain officers visiting, occasionally, some randomly selected lecture venues to check whether the lectures actually hold. The approach has never been effective as: 1) the lecture policing officers themselves are not sufficiently committed to the task and 2) the process itself is susceptible to falsification.

With the proposed LEMS, the QAP lecture policing officer will no longer have to roam the campus to check lecture status; rather an appointed student in the same class, who is anonymous to the lecturer, will send the updates from wherever the lecture might have held.

We have shown that the system can provide a variety of standalone and statistical reports on individual courses, lecturers, departments and faculties. Such reports can be used by the QAP to deduce facts about the commitments of lecturers to their assigned tasks as well as the global perceptions of the man-hour inputs of the lecturers in a selected department and/or faculty. These reports will assist the QAP unit in identifying problem areas and making appropriate recommendations to the management of the university's management.

We intend to integrate LEMS with the lecturers' appraisal and promotion process to help the appropriate authorities award the commenurate scores to individual lecturers in the area of workload, man-hour inputs and commitment to duty.

\section{REFERENCES}

[1] White, B. R., Education, I., Cowhy, J., Stevens, W. D., \& Sporte, S. E. (2012). Designing and Implementing the Next Generation of Teacher Evaluation Systems Lessons Learned from Case Studies in Five Illinois Districts. Accessed from: https://consortium.uchicago.edu/sites/default/files/public ations/Teacher\%20Evaluation\%20Policy\%20Brief1_0.p df

[2] Curtis, B. R. (2012). Building It Together: The Design and Implementation of Hillsborough County Public Schools ' Teacher Evaluation System, (March). The Aspen Institute, Washington D.C.

[3] Liu, Z., \& Zhao, G. (2008). The Analysis , Design and Implementation of University Teachers Evaluation System Based on UML Technology, 1160-1163. International Conference on Computer Science and Software Engineering. Vol 6, 12-14

[4] Zhao, Q., \& Meng, G. (2008). The Analysis of Indicators in Teachers Evaluation Based on Rough Set. Intelligent Information Technology Application Conference, Vol 2, pp8-12.

[5] Yao-hua, S. (2017). The construction of excellent teachers teaching evaluation system in the blended learning environment, proceedings of the 9thInternational Conference on Measuring Technology and Mechatronics Automation, Changsha, Hunan, China

[6] Yali, S., \& Bisheng, F. (2015). The design and implementation of Teaching Evaluation System Based on Web, paper presented at 7th International Conference on Information Technology in Medicine and Education (ITME)

[7] Wood, J. and Yeager, M. (2014). The Quality Framework: A Tool for Building Evaluation System that Improve Instruction. A paper by Educational Counsel

[8] Zhang, F., Fang, W., Zhou, C., \& Liu, Z. (2011). A Brief Study on Teaching Evaluation System Based on Fuzzy Rule with Scientific Teaching Materials. Advances in 
Computer Science, Environment, Ecoinformatics and Education pp.99-105

[9] Inko-Tariah, D. C. (2013). Attitude of Lecturers towards Student's Evaluation of Their Teaching Effectiveness in Nigerian Universities. Journal of Education and Practice vol 4 (15), pp. 21-26

[10] Igwe, R. O., \& Rufai, S. A. (2012). An Evaluation of Teachers Service Delivery in Nigeria: Measures for Programme Accountability and Improvement. Humanity and Social Sciences Journal7(2), 121-127
[11] Ochoche, A. (2008). A Proposed Evaluation Technique for Computer Science Studies in Primary and Secondary Schools. Leonardo Electronic Journal of Practices and Technologies (12), 139-150.

[12] Adeyemo, E. O. (2015). Lecturers' Perception towards Students Assessment of Their Teaching Effectiveness in a Nigerian University, International Journal of Psychology and Behavioural Sciences5(5), 184-192

[13] 